\title{
Smoking effects on quality of life of allergic rhinitis patients after sublingual immunotherapy*
}

\author{
Michael Katotomichelakis' ${ }^{1}$ Gregory Tripsianis², Alexandra Daniilidi', \\ Dimitrios Cassimos' ${ }^{1}$, Christos Kourousis', Theodosia Vogiatzaki', \\ Vassilios Danielides ${ }^{1}$ \\ Rhinology 53: 325-331, 2015 \\ DOI:10.4193/Rhino14.245 \\ *Received for publication: \\ 'Department of Otorhinolaryngology, Medical School, Democritus University of Thrace, Alexandroupolis, Evros, Greece \\ October 6, 2014 \\ ${ }^{2}$ Department of Statistics, Medical School, Democritus University of Thrace, Alexandroupolis, Evros, Greece \\ Accepted: June 11, 2015
}

\begin{abstract}
Background: Although tobacco smoking is of great concern, there is no evidence for the effects of smoking on quality of life (QoL) results after sublingual immunotherapy (SLIT).
\end{abstract}

Objective: This study aims to explore any association between smoking habits (duration and quantity) and QoL results after SLIT in allergic rhinitis (AR).

Methodology: One hundred and sixty three patients following SLIT for AR were participated. SLIT efficacy related to smoking was prospectively evaluated by means of validated widely used QoL questionnaires, either for assessing psychology (Zung Anxiety Scale, State-Trait Anxiety Inventory, Zung Depression Scale and Beck Depression Inventory) or generic (Short Form-36) ones, preand immediately upon cessation of SLIT. Smoking habits were expressed in pack-years.

Results: Significant improvement of total symptoms score (T5SS) and of all QoL questionnaires' results were observed in our patients' group, both for smokers and non smokers. The comparison of changes between smokers and non smokers, controlling for the effect of all patients' characteristics, showed that there was no significant differences on improvement values. Additionally multivariate linear regression analysis revealed that the effect of pack-years on the QoL scales was not significant.

Conclusions: Our results suggest that smoking habits (quantity of daily smoking and duration) do not influence the success of SLIT with regards to QoL outcomes.

Key words: allergic rhinitis, quality of life, smoking habits, sublingual immunotherapy, pack-years

\section{Introduction}

Allergic rhinitis (AR) represents a common disorder with considerable increase worldwide over the last decades ${ }^{(1-3)}$ with a subsequent negative effect on patients' quality of life (QoL) (4-6). Sublingual Immunotherapy (SLIT) - a cost effective therapy for AR - along with allergen avoidance and drug therapy, is a cornerstone in the management of respiratory allergy ${ }^{(7)}$. SLIT is related with the modification of the natural history of respiratory allergy while maintaining its effects ${ }^{(7-9)}$; the above lead to decreased inflammatory response and subsequent improvement on patients' QoL after exposure to allergens ${ }^{(10-18)}$.
The negative effects of smoking on upper airway diseases are extensively and well documented (19-21); moreover smoking has been described for its immunomodulating effects ${ }^{(22,23)}$. However to our knowledge, although the beneficial effects of SLIT on patients' $\mathrm{QoL}$ are already extensively described, there is no clear evidence for the effects of smoking on SLIT with regards to patients' QoL results. This means that questions such as how smoking is correlated to QoL in AR patients, and if smokers are good candidates for SLIT according to their QoL outcomes have not been adequately addressed in literature and need to be further explored. Moreover there is no evidence for the relati- 
onship between quantity and duration of smoking (pack-years) and SLIT outcomes. The clinical importance is that this data may prove valuable for otolaryngologists deciding on the optimal management of smokers suffering from AR, facilitating case selections and counselling patients about the anticipating benefit for their QoL after SLIT.

Accordingly, the aims of the present study were to prospectively evaluate the overall effects of smoking on post-treatment outcomes (QoL) in AR patients after SLIT and to determine if smoking habits (quantity of daily smoking and duration, expressed in pack-years), influence the success of therapy for AR, regarding QoL results.

\section{Methods}

\section{Study group}

This study represents part of a prospective study for QoL assessment of AR patients that was carried out in the rhinology clinic of the tertiary academic hospital of Alexandroupolis/ Greece. Five hundred and eighty five patients were examined during a four and a half-year period (March 2009-September 2013). One hundred and sixty three patients (N:27.8\%) were diagnosed with AR. Diagnosis was based on clinical examination that included history, nasal endoscopy, sinus computed tomography scanning, skin prick testing (SPT) for atopy, test of pulmonary function by spirometry and olfactory testing. There were no pathognomonic findings on endoscopy and CT scan in our study group. Only subjects who suffered from moderateto-severe persistent perennial AR for at least 2 years resistant to other medical therapies and a positive SPT (mean diameter of wheal, $\geq 3 \mathrm{~mm}$ ) were included in the study group. Criteria for exclusion were history of chronic rhinosinusitis, nasal polyps or malignancy, previous nasal operation, history of anaphylaxis or angioedema and dermographism, immunotherapy treatment during the last 5 years and relative contraindications to immunotherapy. All patients fulfilled the criteria of AR according to 2008 ARIA guidelines ${ }^{(24)}$. None of the subjects used oral or nasal corticosteroids 4 weeks prior to inclusion-although no inhibitory effect either of nasal or systemic short term corticosteroids have been described on SPTs ${ }^{(25)}$ - and oral antihistamines 1 week prior to SPT, according to the protocol we applied for the study of AR patients. All subjects before treatment underwent a brief psychiatric interview to exclude any subject with preexisting psychiatric disorder. Smokers' cohort included patients who smoked at the time of initial treatment and didn't change their smoking habits during SLIT; whereas those who smoked only in the past were excluded, because the impact of prior smoking may be a confusing factor on results. Smoking habits were measured in pack per years, calculated by the number of packs smoked per day multiplied by the smoking years. Study members were categorized as never smokers if their lifetime
Table 1. Sensitivities and antigens used for Sublingual Immunotherapy (SLIT) in AR patients.

\begin{tabular}{|lc|}
\hline Antigens & $\begin{array}{c}\text { No. of patients } \\
(\%)\end{array}$ \\
\hline Dernatophagoides mix (farinae,pteronyssinus) & $68(41.7)$ \\
\hline Dernatophagoides mix, Grass mix & $34(20.9)$ \\
\hline Dernatophagoides mix, alternaria alternate & $20(12.3)$ \\
\hline Dernatophagoides mix, olive & $11(6.7)$ \\
\hline Dernatophagoides mix, parietaria & $9(5.5)$ \\
\hline Dernatophagoides mix, epithelium & $4(2.5)$ \\
\hline Dernatophagoides mix, other antigens & $17(10.4)$ \\
\hline
\end{tabular}

pack-year history was nil. Passive smoking was not included in the study criteria due to the fact that more or less most Greek people are potentially passive smokers. The study protocol was approved by the local Institutional Review Board. All subjects signed informed consent. The study was performed in accordance with the Declaration of Helsinki/Hong Kong.

\section{Symptoms evaluation}

Overall symptoms of AR were assessed using the Total 5 Symptoms Score (T5SS) that includes the symptoms of nasal discharge (rhinorrhea), nasal congestion, itchy nose, sneezing, and itchy eyes. All symptoms were graded from 0 (absent) to 3 (very troublesome), with total scores ranging from 0-15. Olfactory function was assessed using "Sniffin' Sticks" test package (Burghart, Wedel, Germany) ${ }^{(26,27)}$. The "Sniffin' Sticks" test battery consists of three elaborate tests of olfactory function: odor threshold (OT), odor discrimination (OD), and odor identification $(\mathrm{OI})$ and the results of the three tests are combined to form an overall score called "composite threshold-discrimination-identification score" (TDI). Each battery is consisted of 112 felt-tipped pens (sticks). Every stick contained $4 \mathrm{~mL}$ of liquid odorant or odorant dissolved in propylene glycol, an antibacterial substance ${ }^{(26,27)}$. TDI score ranges from 0 to 48 (values of 15 or less represent anosmia, values between 16 and 34.5 represent hyposmia and values over 34.5 represent normosmia for the mild climate conditions in Greece) ${ }^{(27)}$. SPTs were performed as proved to have the best positive predictive value (48.7\%) for the diagnosis of AR compared to the Phadiatop ${ }^{\circledR}$ (43.5\%) or total serum IgE (31.6\%) (24). SPTs were evaluated as described by the European Academy of Allergy and Clinical Immunology ${ }^{(28)}$. The antigen panel consisted of common aeroallergens and more specifically dermatophagoides farinae, dermatophagoides pteronyssinus, cat and dog epithelium, grasses mix, parietaria, olive tree, poplar, alternaria alternate, cladosporium, aspergillus, cypress, pine. 
Sensitivities and antigens used for SLIT are presented in Table 1.

Patients' QoL assessment was achieved by means of a widely used general health survey (Short Form -SF-36) and four validated widely used generic questionnaires sensitive and specific for delineating mental health (Zung Anxiety Scale-ZAS, State and Trait Anxiety Inventory-STAI, Beck Depression Inventory$\mathrm{BDI}$ and Zung Depression Scale-ZDS) ${ }^{(29)}$. All subjects had to complete all the above questionnaires at the beginning of the study and immediately upon cessation of SLIT. SF-36 is a widely used general-health related survey, already validated in allergic respiratory disease ${ }^{(4)}$, that explores QoL in eight domains covering both physical and mental health from the patient's point of view with chronic diseases ${ }^{(30,31)}$. Scores range from 0 to 100 , with a higher score representing better functioning ${ }^{(30,31)}$. The other four questionnaires were used to assess patients' QoL outlining their mental health. Anxiety symptoms were assessed by means of ZAS ${ }^{(32)}$ and STAI ${ }^{(33)}$ scales translated and validated in Greek. ZAS is a self-rating scale, which explores levels of anxiety ${ }^{(32)}$. STAl is an instrument consisting of two parts, one that refers to anxiety due to a specific condition (state), and another one that refers to the general tendency of the subject to react anxiously (trait) ${ }^{(33)}$. Each of these parts has 20 questions, that their answers are graded from 1 to 4. Depression was assessed using the Greek validated versions of BDI ${ }^{(34)}$ and ZDS ${ }^{(35)}$. BDI consists of 21 self reporting items graded from 0 to 3 , according to the level of depressive symptomatology ${ }^{(34)}$. ZDS ${ }^{(35)}$ is another self-administered instrument with a structure similar to ZAS, measuring depression. It consists of 20 items graded from 1 to 4 assessesing depression. Higher scores in all psychometric scales indicate higher levels either of anxiety or depression.

\section{Treatment protocol}

SLIT is considered beneficial to pharmacotherapy in moderate to severe cases, even for patients' QoL ${ }^{(10-18)}$. It consists of the administration of gradually increasing doses of specific allergen extracts to which the patient is sensitized (positive SPT's) and in conjunction to history is considered allergic ${ }^{(7,8)}$. SLIT consisted of Staloral ${ }^{(36)}$ (10 I.R./ml and 300 I.R./ml; Stallergenes, Antony, France; build-up phase 10 I.R./ml for 1 week and then $300 \mathrm{IR} / \mathrm{mL}$ for 1 week gradually increasing every day and maintenance phase 300 I.R./ml eight applications three times a week) or Sublivac (36) (10,000 AUN/ml; HAL Allergy BV, The Netherlands; build-up up-dosing phase lasting 5 days gradually increasing every day and maintenance dosage of 5 droops every day). In polysensitized patients we used a mixture of no more than two antigens, according to SPT's results, history and clinical information.

\section{Statistical analysis}

Statistical analysis of the data was performed using the Statistical Package for the Social Sciences (SPSS), version 19.0 (IBM).
Table 2. Demographics and disease characteristics of AR patients in relation to smoking habits and adjusted pre-treatment scores of psychometric scales.

\begin{tabular}{|c|c|c|c|}
\hline & $\begin{array}{c}\text { Non- } \\
\text { smokers } \\
(n=115)\end{array}$ & $\begin{array}{l}\text { Smokers } \\
(n=48)\end{array}$ & p-value \\
\hline Male gender [no (\%)] & $71(61.7)$ & $36(75.0)$ & 0.104 \\
\hline Age [years; mean (SD)] & $\begin{array}{c}31.97 \\
(11.17)\end{array}$ & $\begin{array}{c}36.92 \\
(17.33)\end{array}$ & 0.072 \\
\hline Socio-economic status [no (\%)] & & & 0.047 \\
\hline Low & $5(4.3)$ & $4(8.3)$ & \\
\hline Medium & $19(16.5)$ & $15(31.3)$ & \\
\hline High & $91(79.1)$ & $29(60.4)$ & \\
\hline $\begin{array}{l}\text { Smoking duration [years; } \\
\text { median (IQR)] }\end{array}$ & - & $\begin{array}{c}14 \\
(10-35)\end{array}$ & - \\
\hline Asthma presence [no (\%)] & $12(10.4)$ & $12(25.0)$ & 0.017 \\
\hline T5SS score [mean (SD)] & $9.56(2.17)$ & $\begin{array}{l}10.32 \\
(2.06)\end{array}$ & 0.038 \\
\hline TDI score [mean (SD)] & $\begin{array}{l}35.91 \\
(2.75)\end{array}$ & $\begin{array}{c}28.84 \\
(12.88)\end{array}$ & $<0.001$ \\
\hline Olfactory function [no (\%)] & & & $<0.001$ \\
\hline Normosmics & 85 (73.9) & $23(47.9)$ & \\
\hline Hyposmics & $30(26.1)$ & $13(27.1)$ & \\
\hline Anosmics & $0(0.0)$ & $12(25.0)$ & \\
\hline \multicolumn{4}{|c|}{ Adjusted pre-treatment scores of Psychometric scales } \\
\hline SF-36 & $\begin{array}{l}78.97 \\
(1.06)\end{array}$ & $\begin{array}{l}81.18 \\
(1.87)\end{array}$ & 0.358 \\
\hline Zung Anxiety Scale & $\begin{array}{l}32.15 \\
(0.50)\end{array}$ & $\begin{array}{l}30.51 \\
(0.88)\end{array}$ & 0.147 \\
\hline State-Trait Anxiety Inventory & $\begin{array}{l}38.07 \\
(0.68)\end{array}$ & $\begin{array}{l}39.39 \\
(1.20)\end{array}$ & 0.394 \\
\hline Zung Depression Scale & $\begin{array}{l}33.61 \\
(0.50)\end{array}$ & $\begin{array}{l}34.66 \\
(0.89)\end{array}$ & 0.359 \\
\hline Beck Depression Inventory & $\begin{array}{r}5.37 \\
(0.46)\end{array}$ & $\begin{array}{c}5.88 \\
(0.71)\end{array}$ & 0.551 \\
\hline
\end{tabular}

Normally distributed quantitative variables were expressed as mean (standard deviation, SD); non-normally distributed quantitative variables were expressed as median (interquartile range, IQR); qualitative variables were expressed as frequencies (percentage, \%).

The normality of quantitative variables was ascertained with Kolmogorov-Smirnov test. Normally distributed quantitative variables were expressed as mean \pm standard deviation (SD), while 
Table 3. Scores of Quality of life (QoL) questionnaires results pre- and post-treatment in smokers and non-smokers. Data are expressed as mean values (standard deviation, SD).

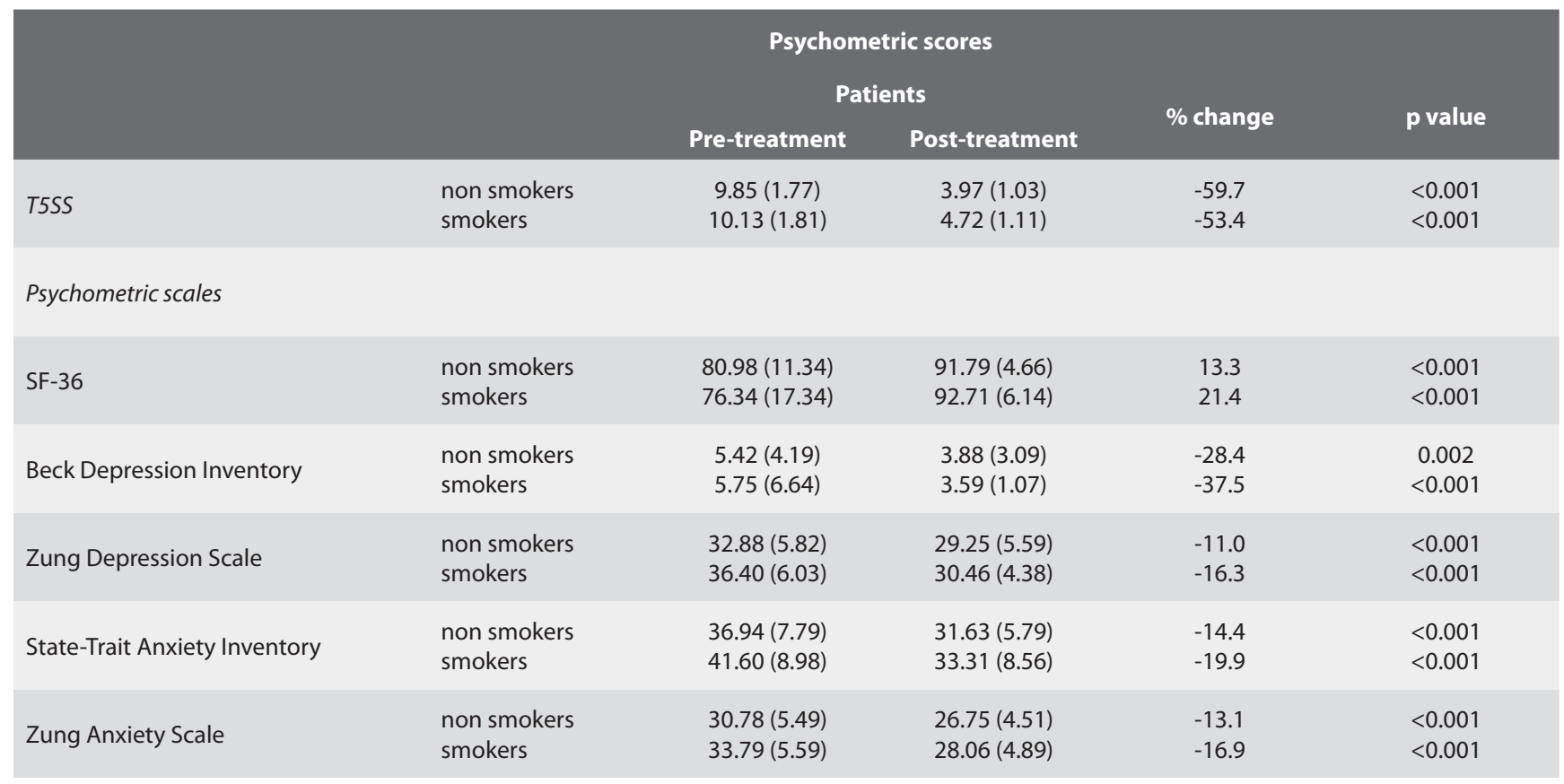

p values refer to comparison between pre- and post- treatment scores.

non-normally distributed variables were expressed as median and interquartile range (IQR, 25th to 75th percentile); quantitative variables were expressed as frequencies and percentages (\%). The chi-square test, Student's t test and Mann-Whitney Utest were used to assess differences of demographic and disease characteristics between smokers and non smokers. One-way analysis of covariance (ANCOVA) was performed to investigate the effect of smoking on (i) pre-treatment scores and (ii) posttreatment changes of the scores of QoL questionnaires, adjusting for all potential confounders. Since the distribution of BDI score was skewed, the statistical analysis was performed on the log-transformed scores. The effect size (ES) of smoking habits on the changes of the scores of quality of life (QoL) questionnaires of allergic rhinitis patients after treatment was described in terms of Cohen's d. An ES of 0.2 to 0.3 represents a "small" effect, around 0.5 a "moderate" effect and 0.8 to infinity, a "large" effect ${ }^{(37)}$. To assess the independent effect of the number of packyears on the post-therapy changes of the QoL questionnaires multivariate linear regression analysis was constructed. All tests were two tailed and statistical significance was considered for $p$ values of less than 0.05 .

\section{Results}

The study group included one hundred and sixty three patients suffering from $A R$, with a mean age of $33.42 \pm 13.42$ years (range, 17-66; median age 29 years). One hundred and seven
(65.6\%) out of them were males, with a mean age of $34.39 \pm$ 14.07 years and 56 (34.4\%) were females, with mean age 31.57 \pm 11.97 years. A history of current smoking was reported in 48 (29.5\%) patients, while 115 patients (70.5\%) had never smoked. Demographics and disease characteristics of the patients in relation to their smoking habits are presented in Table 2 . There were no statistically significant differences in gender $(p=0.104)$ and age ( $p=0.072$ ) between smokers and non smokers; on the contrary, more smokers belonged to the low socio-economic class compared to non smokers ( $p=0.047$ ). Regarding clinical characteristics asthma history $(25.0 \%$ vs $10.4 \%, \mathrm{p}<0.017)$ and olfactory dysfunction $(12.88 \%$ vs $2.75 \%, \mathrm{p}<0.001)$ were more frequent among smokers than non smokers. Also smokers presented higher T5SS ( 10.32 vs $9.56, p=0.038$ ) compared to non smokers. Since there were some significant differences in demographic and disease characteristics among groups, analysis of covariance was performed to investigate the effect of smoking on patients' QoL, controlling for the effect of all possible confounders. The adjusted pre-treatment scores of all QoL questionnaires results were compared between smokers and non smokers (Table 2) in order to assess the independent effect of smoking on patients' QoL. There was no statistically significant differences in the pre-treatment scores in any of the questionnaires used (SF-36: $p=0.358$; ZAS: $p=0.147$; STAI: $p=0.394$; ZDS: $p=0.359 ; B D I: p=0.551$ ). 
Table 4. Adjusted changes of the scores of quality of life (QoL) questionnaires of AR patients after treatment in relation to smoking. Data are expressed as adjusted mean values (standard error, SE).

\begin{tabular}{|c|c|c|c|c|c|}
\hline & $\begin{array}{l}\text { Non- } \\
\text { smo- } \\
\text { kers }\end{array}$ & $\begin{array}{l}\text { Smo- } \\
\text { kers }\end{array}$ & $\begin{array}{c}\text { Mean dif- } \\
\text { ference }(95 \% \\
\text { Cl) }\end{array}$ & $\begin{array}{c}p \\
\text { value }\end{array}$ & $\begin{array}{l}\text { Co- } \\
\text { hen's } \\
\text { d }\end{array}$ \\
\hline SF-36 & $\begin{array}{l}12.13 \\
(0.77)\end{array}$ & $\begin{array}{l}13.20 \\
(1.35)\end{array}$ & $\begin{array}{c}-1.06 \\
(-4.48 \text { to } 2.35)\end{array}$ & 0.539 & 0.13 \\
\hline $\begin{array}{l}\text { Zung Anxiety } \\
\text { Scale }\end{array}$ & $\begin{array}{l}-4.58 \\
(0.40)\end{array}$ & $\begin{array}{l}-4.43 \\
(0.71)\end{array}$ & $\begin{array}{c}-0.15 \\
(-1.96 \text { to } 1.65)\end{array}$ & 0.867 & 0.03 \\
\hline $\begin{array}{l}\text { State-Trait Anxi- } \\
\text { ety Inventory }\end{array}$ & $\begin{array}{l}-5.33 \\
(0.82)\end{array}$ & $\begin{array}{l}-8.13 \\
(1.41)\end{array}$ & $\begin{array}{c}2.80 \\
(-0.82 \text { to } 6.42)\end{array}$ & 0.128 & 0.31 \\
\hline $\begin{array}{l}\text { Zung Depression } \\
\text { Scale }\end{array}$ & $\begin{array}{l}-4.28 \\
(0.36)\end{array}$ & $\begin{array}{l}-4.37 \\
(0.63)\end{array}$ & $\begin{array}{c}-0.08 \\
(-1.50 \text { to } 1.67)\end{array}$ & 0.917 & 0.02 \\
\hline $\begin{array}{l}\text { Beck Depression } \\
\text { Inventory }\end{array}$ & $\begin{array}{l}-2.09 \\
(0.48)\end{array}$ & $\begin{array}{l}-2.64 \\
(0.77)\end{array}$ & $\begin{array}{c}-0.55 \\
(-1.32 \text { to } 2.43)\end{array}$ & 0.559 & 0.11 \\
\hline
\end{tabular}

Analysing the AR patients' group received SLIT pre- and after cessation of treatment, a significant improvement of T5SS and the scores of all QoL questionnaires results was observed both for non smokers and smokers as presented in Table 3. The adjusted changes of the scores of all QoL questionnaires results were compared between smokers and non smokers (Table 4) in order to assess the independent effect of smoking habits on patients' QoL recovery. Analysis of covariance controlling for the effect of all patients' characteristics, revealed that there was no significant differences on improvement of all QoL questionnaires between smokers and non smokers (all $\mathrm{p}>0.05$ ).

In order to assess the effect of the quantity and duration of smoking on the improvement of QoL's outcomes, the number of pack-years was calculated for each smoker, multiplying the number of packs smoked per day and the number of smoking years. So in our smokers' cohort the number of packs smoked per day ranged from 0.5 to 2 packs, with a median value of 1 pack per day, while smoking duration ranged from 10 to 60 years with a median duration of 14 years. Based on the number of packs smoked per day and the number of smoking years, it was found a median pack-year of 21 (range from 10 to 60). Multivariate linear regression analysis revealed that the effect of pack-years on the psychological scales was not significant (SF-36: beta regression coefficient (SE), $b=0.047(0.081), p=0.561$; ZAS: $b=0.070$ (0.046), $p=0,135)$; STAI $(b=0.100(0.080), p=0.215$; ZDS: $b=0.107$ (0.054), $p=0.054 ; B D I: b=-0116(0.160), p=0.471)$.

\section{Discussion}

It is widely known that AR affects patients' QoL ${ }^{(4-6)}$. Moreover the burden of smoking on nasal mucosa and its immunomodulating effects on AR are extensively discussed ${ }^{(14-18)}$. Augmented reactivity to irritants is a phenotypic characteristic of both nonallergic and allergic rhinitis, but the role of tobacco smoking in rhinitis is still a matter of debate ${ }^{(38)}$. There are studies ${ }^{(39)}$ which demonstrated that smoking inconstantly increases total and specific $\lg \mathrm{E}$ and the $\lg \mathrm{E}$ sensitization to some occupational allergens, as well as being associated with nasal symptoms. However, in the absence of longitudinal studies, it is difficult to establish whether smoking is a causative factor of allergy or not. Secondly, in healthy subjects, smoking was not found to impair nasal QoL ${ }^{(40)}$. To the best of our knowledge this is the first study to provide evidence for the effects of smoking habits on AR patients' $Q$ oL results after SLIT. The findings are very important as most clinical trials in rhinitis nowadays include a measure of health-related QoL as a primary outcome, and many clinicians are incorporating QoL into routine clinical assessments ${ }^{(41,42)}$. To get an overall picture of a patient's health status and to provide general conclusions that could be used either in every day clinical practice or in future studies to allow comparisons between different diseases, conditions or treatments, we used validated, widely used generic questionnaires for QoL assessment. It should be mentioned that this study follows our recent work (43) that explored how smoking affects QoL outcomes, however in patients suffering from chronic rhinosinusitis (CRS) who subjected to endoscopic sinus surgery. Both studies' findings as a whole are very important as refer to common chronic sinonasal diseases and reveal how smoking - a modern habit - affects treatment results.

In this study we first examined an important issue regarding if active smoking status should be considered a contra-indication or not for SLIT. We observed that all patients irrespective to their smoking habits presented a significant improvement either on their total symptoms score or on all QoL questionnaires' results after treatment. These findings suggest that smoking status should not be considered a contra-indication to SLIT for AR patients, and there is no selection limits related to smoking habits. Complementary to the statistical significance (p-values), either the upper or lower limits of the $95 \% \mathrm{Cl}$ of the QoL changes between non-smokers and smokers (i.e. -1.06 points change in SF- $36,-0.08$ points in ZDS etc.) or the Cohen's $\mathrm{d}$ effect size, both indicate no effect of smoking in changes of QoL ${ }^{(37)}$. There are population studies with variable results for the association between tobacco smoking and $A R{ }^{(44)}$, with reports of a lower prevalence of AR in smokers ${ }^{(45,46)}$, as well as the opposite ${ }^{(47)}$, and the question of how smoking affects SLIT results related to patients' QoL outcomes still remains without a clear answer. There are some studies to support the negative effect of smoking on SLIT efficacy. Marogna et al. ${ }^{(48)}$ reported that smoking reduces the efficacy of SLIT although still exerts an overall positive significant clinical response. Similarly Ganonica et al. ${ }^{(49)}$ in a review article mentioned that from the therapeutic point of view, tobacco smoking is associated with a lesser response to oral steroids, inhaled corticosteroids and leukotrienes receptor 
antagonists, however with no evidence for SLIT effects. On the other hand it is interesting to mention that Hancox et al. ${ }^{(22)}$ and Sopori et al. ${ }^{(23)}$ regarding the immunomodulating effects of cigarette smoking believe that the development of atopy is not clear. Components of cigarette smoke, such as nicotine, possibly enhance suppressor T-cell function and suppress Th cells ${ }^{(23)}$.

\section{Additionally we observed that not only smoking but also the} duration and quantity of daily smoking didn't affect SLIT results with regards to patients' QoL outcomes. Multivariate linear regression analysis revealed that the effect of pack-years on the psychological scales was not significant, finding that is clinically important to be mentioned. On the contrary in ours previous work for CRS ${ }^{(43)}$, we found that quantity and duration of smoking were significantly associated with worse postoperative results in all QoL questionnaires. The importance of assessing patients' QoL to describe the effects of a specific treatment in AR in clinical practice, as well as arguments raised on the effects of smoking on treatment results, stress the need for more perspective studies in the future with larger cohorts using more -specific for AR- QoL instruments.
In conclusion, we showed that AR patients experience beneficial QoL results after SLIT irrespective to their smoking habits. Both smokers and non-smokers are significantly improved after treatment and there is no contra-indication to SLIT therapy related to smoking habits. These findings are of great clinical importance in every day clinical practice for case selection for SLIT.

\section{Author contributions}

MK designed, conceived and conducted the clinical study, investigated and analyzed the data, wrote article; GT made all the statistical analysis of the data, and wrote article; AD collected all data (clinical data, questionnaires), participated in the conduction of the clinical study, gave clinical support and wrote the manuscript; DC, CK and TV conceived the clinical study, gave clinical support, analyzed the data, wrote the article; VD designed, conceived and conducted the study, analyzed the data, wrote the article and approved the final version for publication.

\section{Conflict of interest}

No conflict of interest exists.

\section{Conclusions}

\section{References}

1. Canonica GW, Bousquet J, Mullol J, Scadding GK, Virchow JC. A survey of the burden of allergic rhinitis in Europe. Allergy 2007; 62 (suppl 85):S17-S25

2. Björkstén B, Clayton T, Ellwood P, Stewart A, Strachan D. Worldwide time trends for symptoms of rhinitis and conjunctivitis: Phase III the International Study of Asthma and Allergies in Childhood. Pediatr. Allergy Immunol. 2008; 19:110-124.

3. Greiner AN, Hellings PW, Rotiroti G, Scadding GK. Allergic rhinitis. Lancet 2011; 378:2112-2122

4. Bousquet PJ, Demoly P, Devillier P, Mesbah K, Bousquet J. Impact of allergic rhinitis symptoms on quality of life in primary care. Int Arch Allergy Immunol.2013; 160:393400.

5. Bhattacharyya N. Functional limitations and workdays lost associated with chronic rhinosinusitis and allergic rhinitis. Am J Rhinol Allergy 2012; 26:120-122.

6. Izquierdo-Domínguez A, Valero AL, Mullol J. Comparative analysis of allergic rhinitis in children and adults. Curr Allergy Asthma Rep. 2013; 13:142-151.

7. Canonica GW, Cox L, Pawankar R, et al. Sublingual immunotherapy: World Allergy Organization position paper 2013 update. World Allergy Organ J. 2014; 28; 7(1):6

8. Zuberbier T, Bachert C, Bousquet PJ, et al. $G^{2} L E N / E A A C l$ pocket guide for allergenspecific immunotherapy for allergic rhinitis and asthma. Allergy 2010; 65:1525-1230.

9. Radulovic S, Calderon MA, Wilson D,
Durham S. Sublingual immunotherapy for allergic rhinitis. Cochrane Database Syst Rev. 2010; 8(12):CD002893.

10. Hankin CS, Cox L, Lang D, et al. Allergen immunotherapy and health care cost benefits for children with allergic rhinitis: a large-scale, retrospective, matched cohort study. Ann Allergy Asthma Immunol.2010; 104:79-85.

11. Dretzke J, Meadows A, Novielli N, Huissoon A, Fry-Smith A, Meads C. Subcutaneous and sublingual immunotherapy for seasonal allergic rhinitis: a systematic review and indirect comparison. J Allergy Clin Immunol.2013; 131:1361-1366.

12. Radulovic S, Wilson D, Calderon M, Durham S. Systematic reviews of sublingual immunotherapy (SLIT). Allergy 2011; 66:740-752.

13. Baiardini I, Braido F, Tarantini F, et al. ARIAsuggested drugs for allergic rhinitis: what impact on quality of life? A GA2LEN review. Allergy 2008; 63:660-669.

14. Ciprandi G, Cadario G, Valle C, et al. Sublingual immunotherapy in polysensitized patients: effect on quality of life. J Investig Allergol Clin Immunol. 2010; 20:274-179.

15. Lin SY, Erekosima N, Kim JM, et al. Sublingual immunotherapy for the treatment of allergic rhinoconjunctivitis and asthma: a systematic review. JAMA 2013; 309:1278-1288.

16. Wise SK, Woody J, Koepp S, Schlosser RJ. Quality of life outcomes with sublingual immunotherapy. Am J Otolaryngol. 2009; 30:305-311
17. Walker SM, Durham SR, Till SJ, et al. British Society for Allergy and Clinical Immunology: Immunotherapy for allergic rhinitis. Clin Exp Allergy 2011; 41:1177-1200.

18. Petalas K, Durham SR. Allergen immunotherapy for allergic rhinitis. Rhinology 2013; 51:99-110.

19. Katotomichelakis M, Balatsouras D, Tripsianis G, et al. The effect of smoking on the olfactory function. Rhinology 2007; 45:273-280.

20. Annesi-Maesano I, Oryszczyn MP, Neukirch F, Kauffmann F. Relationship of upper airway disease to tobacco smoking and allergic markers: a cohort study of men followed up for 5 years. Int Arch Allergy Immunol 1997; 114:193-201.

21. Benninger MS. The impact of cigarette smoking and environmental tobacco smoke on nasal and sinus disease: a review of the literature. Am J Rhinol. 1999; 13:435438

22. Hancox RJ, Welch D, Poulton R, et al. Cigarette smoking and allergic sensitization: a 32-year population-based cohort study. J Allergy Clin Immunol. 2008; 121:38-42.

23. Sopori M. Effects of cigarette smoke on the immune system. Nat Rev Immunol 2002; 2:372-377.

24. Bousquet J, Khaltaev N, Cruz AA, et al. Allergic Rhinitis and its Impact on Asthma (ARIA) 2008 update (in collaboration with the World Health Organization, GA(2)LEN and AllerGen). Allergy. 2008; 63 Suppl 86:8160.

25. Bousquet J, Heinzerling L, Bachert $C$, et al. 
Practical guide to skin prick tests in allergy to aeroallergens. Allergy 2012;67:18-24.

26. Hummel T, Kobal G, Gudziol H, Mackay-Sim A. Normative data for the "Sniffin' Sticks" including tests of odor identification, odor discrimination, and olfactory thresholds: an upgrade based on a group of more than 3,000 subjects. Eur Arch Otorhinolaryngol. 2007; 264:237-243.

27. Katotomichelakis M, Balatsouras D, Tripsianis G, Tsaroucha A, Homsioglou E, Danielides $V$. Normative values of olfactory function testing using the 'Sniffin' Sticks' Laryngoscope 2007; 117:114-120.

28. Dreborg S. EAACI Subcommittee on Skin Tests. Skin tests used in type I allergy testing. Position Paper. Allergy 1989; 44 (suppl.10):S22-S31.

29. Addolorato G, Ancona C, Capristo E, et al. State and trait anxiety in women affected by allergic and vasomotor rhinitis. Psychosom Res. 1999; 46:283-289.

30. Ware JE. The SF-36 Health Survey; in: Spilker B (ed). Quality of life and pharmaeconomics in clinical trials. Philadelphia, PA. LipincottRaven, 1996; pp 337-346.

31. Pappa E, Kontodimopoulos N, Niakas D. Validating and norming of the Greek SF-36 Health Survey. Qual Life Res. 2005; 14:14331438.

32. Zung W. A rating instrument for anxiety disorders. Psychosomatics 1971; 12: 371-379.

33. Spielberger CD, Gorsuch RL, Lushene R, Vagg PR, Jacobs GA. Manual for the StateTrait Anxiety Inventory. Palo Alto, CA Consulting Psychologists Press: 1983.

34. Beck AT, Ward CH, Mendelson M, Mock J, Erbaugh J. An Inventory for Measuring Depression. Archives of General Psychiatry 1961; 4: 53-63.

35. Fountoulakis KN, lacovides A, Samolis $S$, et al. Reliability, Validity and Psychometric Properties of the Greek Translation of the Zung Depression Rating Scale. BMC Psychiatry 2001; 1:6.

36. Klimek $L$, Sperl A, van Twuijver $E$, et al. A prospective study comparing the efficacy and safety of two sublingual birch allergen preparations. Clin Transl Allergy. 2014; 23:423.

37. Cohen J. Statistical power analysis for the behavioral sciences. (2nd Ed.) Hillsdale, NJ: Lawrence Erlbaum Associates; 1988.

38. Saulyte J, Regueira C, Montes-Martínez A, Khudyakov P, Takkouche B. Active or passive exposure to tobacco smoking and allergic rhinitis, allergic dermatitis, and food allergy in adults and children: a systematic review and meta-analysis. PLoS Med. 2014; 11:11(3):e1001611

39. Peden D, Reed CE. Environmental and occupational allergies. J Allergy Clin Immunol. 2010; 125(2 Suppl 2):S150-160

40. Bousquet PJ, Fabbro-Peray P, Janin N, et al. Pilot study assessing the impact of smoking on nasal-specific quality of life. Allergy 2004; 59:1015-1016

41. Juniper EF. Measuring health-related quality of life in rhinitis. J Allergy Clin Immunol. 1997; 99:742-749.

42. Kremer B, Klimek L, Bullinger M, Mösges R. Generic or disease-specific quality of life scales to characterize health status in allergic rhinitis? Allergy.2001; 56:957-963.

43. Katotomichelakis M, Simopoulos E, Tripsianis G, et al. The effects of smoking on quality of life recovery after surgery for chronic rhinosinusitis. Rhinology 2014; 52:341-347

44. Eriksson J, Ekerljung L, Sundblad BM, et al. Cigarette smoking is associated with high prevalence of chronic rhinitis and low prevalence of allergic rhinitis in men. Allergy. 2013; 68:347-354.

45. Konno S, Hizawa N, Fukutomi Y, et al. The prevalence of rhinitis and its association with smoking and obesity in a nationwide survey of Japanese adults. Allergy 2012; 67:653-660.

46. Wüthrich B, Schindler C, Medici TC, Zellweger JP, Leuenberger P. IgE levels, atopy markers and hay fever in relation to age, sex and smoking status in a normal adult Swiss population. SAPALDIA (Swiss Study on Air Pollution and Lung Diseases in Adults) Team. Int Arch Allergy Immunol 1996; 111:396-402

47. Annesi-Maesano I, Oryszczyn MP, Raherison $C$, et al. Increased prevalence of asthma and allied diseases among active adolescent tobacco smokers after controlling for passive smoking exposure. A cause for concern? Clin Exp Allergy 2004; 34:1017-1023.

48. Marogna M, Massolo A, Colombo F, Isella P, Bruno M, Falagiani P. Children passive smoking jeopardises the efficacy of standard anti-allergic pharmacological therapy, while sublingual immunotherapy withstands. Allergol Immunopathol (Madr). 2011; 39:6067.

49. Baena-Cagnani CE, Gómez RM, BaenaCagnani R, Canonica GW. Impact of environmental tobacco smoke and active tobacco smoking on the development and outcomes of asthma and rhinitis. Curr Opin Allergy Clin Immunol. 2009; 9:136-140.

Professor Vassilios Danielides, MD

PhD

Department of Otorhinolaryngology University Hospital of Alaxandrou-

polis

Alexandroupolis 68100

Greece

Tel: +30-255-107 4544

Fax: +30-255-103 0441

E-mail:vdanielidis@hotmail.com 